\title{
An Optimality-Theoretic Account of English Loanwords in Hawailian
}

\author{
Mustafa Ali Harb \\ Department English, Ball State University, Muncie, IN, USA \\ Email: maharb@bsu.edu
}

Received 13 March 2016; accepted 17 June 2016; published 21 June 2016

Copyright (C) 2016 by author and Scientific Research Publishing Inc.

This work is licensed under the Creative Commons Attribution International License (CC BY).

http://creativecommons.org/licenses/by/4.0/

(c) (i) Open Access

\begin{abstract}
The purpose of this paper is to provide an Optimality-Theoretic (henceforth OT) account of the linguistic phenomenon of borrowing. In particular, it examines English loanwords in Hawaiian from a constraint-based analysis as opposed to a rule-based analysis. Data necessary for this study consisted of some randomly selected Hawaiian words. These loanwords were carefully examined as to realize their phonological changes and how they can be accounted for from an OT standpoint. Several phonological changes, mainly those of the syllable structure of Hawaiian, were examined along with accompanying phonological processes (e.g., epenthesis, degemination, etc.) where applicable. The proposed ranking hierarchy that, the argument goes, could account for all English loanwords in Hawaiian is like this: $\Sigma$ \{NO CODA $>$ MAX-IO $>{ }^{*}$ CC $>$ DEP-IO\}, a state of affairs which confirmed our intuition that the syllable structure of the borrowing language (Hawaiian) prevails over the syllable structure of the donor language (English). In order to establish the ranking argument, comparative tableaux are used. Violations tableaux are also used to demonstrate how the winning configuration beats competitive candidate forms.
\end{abstract}

\section{Keywords}

Optimality Theory (OT), Constraint-Based Analysis, English Loanwords in Hawaiian, Hawaiian Syllable Structure

\section{Introduction}

It is not uncommon that languages borrow from one another for such a wide array of reasons as need, prestige (and lack thereof) or even derogation (Campbell, 2011: p. 58). Borrowed items are not restricted to only lexical items as one might mistakenly assume, but further extend to other linguistic elements, e.g., phonological rules, 
syntactic constructions, semantic associations or even pragmatic strategies. Unlike code switching ${ }^{1}$ where bilinguals normally communicate by mixing two distinct languages, elements of borrowing (i.e., loanwords) get totally integrated into the linguistic patterns of the recipient language. In other words, borrowed items become fully incorporated into the grammatical system of the borrowing language, becoming part of its lexicon, undertaking its morphological formations, and employing its syntactic structures (ibid).

The Hawaiian language (ŌleloHawai'i) is often cited for having borrowed extensively from several other languages including, among others, English, Hebrew, Greek, and Māori. Of those donor languages, English seems to have the most influence on Hawaiian probably due to geographical closeness to the United States (not to mention being one of the 50 U.S. States) and most certainly due to contact situations, the most significant of which is that of English missionaries (Reinecke, 1969). In fact, English is "the most strongly represented [language]" in terms of borrowings (Jones, n.d.).

Of significance to this current study is the phonological realization of loanwords. Borrowed words are adjusted (i.e., phonemically altered) to accommodate the phonology of the recipient language (RL), not that of the donor language (DL). In Optimality Theory (OT) terminology, borrowed words are governed by the same set of universal constraints; however, these constraints are differently ranked in conformity with the phonology of the borrowing language (Prince \& Smolensky, 1993; McCarthy \& Prince, 1993a, 2004). Thus, the overall thrust of this paper is to closely examine the syllable shape of English loanwords in the Hawaiian language and furnish a comprehensive analysis of the syllable shape within the theoretical framework of Optimality Theory (OT).

The paper is organized into the following sections. In the first part, we briefly introduce the topic of this paper. The second section presents background information including the consonant and vocalic inventory of the Hawaiian Language along with a short account of the Hawaiian syllable structure. In the third section, we present the data necessary for this study. The fourth section is devoted to presenting the general premises of OT along with analysis of the data of this study. The final section of this paper is that of conclusion limitations and future recommendations.

\subsection{Background Information}

Named after the largest island in the North Pacific archipelago, the Hawaiian language-along with English-is the official language of the State of Hawaii. According to the US Census Bureau (2009 \& 2010), the current population of Hawaii is estimated at over a million, of whom only 24 thousand can be said to be native speakers of the Hawaiian language, i.e., Hawaiian is the language spoken at home. Historical linguists classify the Hawaiian language as an Austronesian language, which belongs to the Eastern-Polynesian language family.

\subsection{Hawaiian Phonemic Inventory}

According to Maddieson (2011), the range of inventories can be as low as six consonants (e.g., Rotokas of New Guinea] and as high as 141 (e.g., !Xóõ of Botswana). Needless to say, Hawaiian is a melodious language best known for having one of the smallest phonemic inventories in the languages of the world. Hawaiian has only eight consonants [m, n, p, k, h, ?, l, w] and five vowels [i, e, a, u, o]. Table 1 and Table 2 present the phonemic inventory of the Hawaiian language. As for consonants, rows represent manners of articulations and columns stand for places of articulation. In terms of vowels, rows stand for degrees of tongue height, while columns indicate the tongue advancement (Tense) and identify how far forward the tongue is located in the oral cavity during production (i.e., Advanced Tongue Root or ATR).

\subsection{Syllable Structure of Standard Hawaiian}

The syllable structure of Hawaiian is rather simple. Based on Elbert and Pukui (1979) and Kaiao (2003), the syllable structure of Hawaiian is represented as follows:

(C) $\mathrm{V}(\mathrm{V})$

Based on the above-stated formula, the universally unmarked syllable structure in Hawaiian is that of $\mathrm{V}$ or (C)V. In other words, the basic component of the syllable in Hawaiian must have a vowel (either short [V] or long [V:]), optionally preceded by a consonant sound (C).

As seen in Figure 1, the syllable structure is simple indeed (Cf. Arabic or English). Every syllable is composed

${ }^{1}$ For a detailed account of the difference(s) between code switching and borrowing, please see Gumperz (1982). 
Table 1. Consonant inventory of hawaiian².

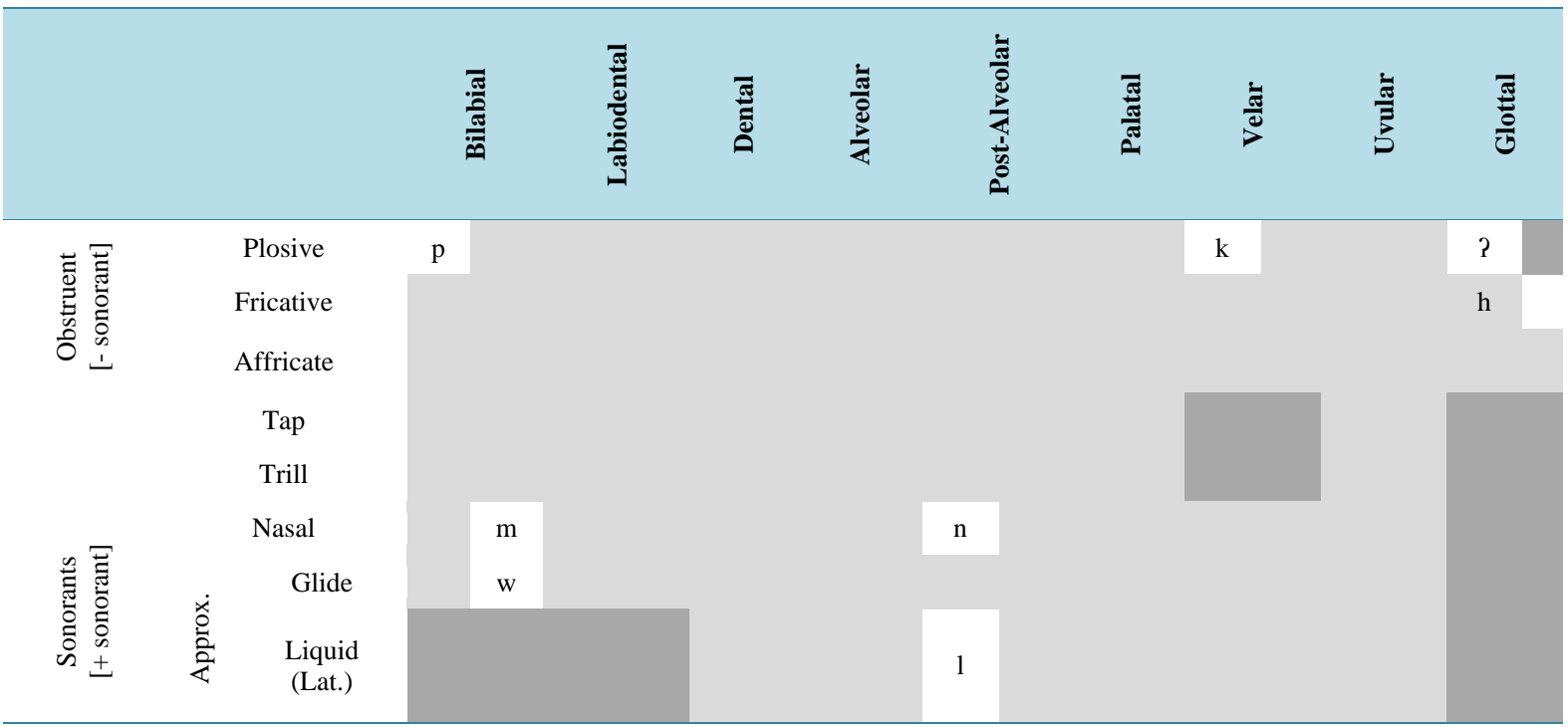

*Dark-shaded areas indicate articulations judged to be humanly impossible. "Light-shaded areas indicate possible articulations in other languages, but not present in Hawaiian.

Table 2. Vowel Inventory of Hawaiian ${ }^{3}$.

\begin{tabular}{cccc} 
& Front Unrounded & Central & Back Rounded \\
\hline High & i & u \\
Mid & e & a & o \\
Low & & \\
\hline
\end{tabular}

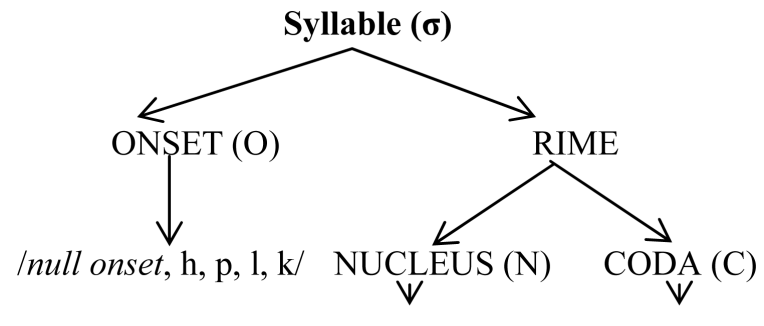

$$
\text { la, i, o, a/ Q }
$$

Figure 1. Universally unmarked syllable in Hawaiian (V; CV).

of an optional consonant (ONSET) and a mandatory vowel (NUCLEUS or PEAK). Codas (either simple or complex) are prohibited (i.e., universal constraint). What this basically means is that each syllable in the language should end in a vowel, and two consonants never appear together.

This is said to be the universally unmarked (most natural/default) form of the syllable in Hawaiian (Figure 2). Consider the following examples:

1) hi (fire): V.CV

2) hi.pa (sheep): CV.CV

3) ho.la (hour): CV.CV

4) ka.la (collar): CV.CV

${ }^{2}$ Both phonemic inventories are one of the contributions of this paper.

${ }^{3} \mathrm{~A}$ vertical line has been inserted to indicate the disagreement between phonetics and phonology. Whereas phoneticians classify vowels as front, central and back, phonologists tend to ignore the notion of central vowels and include them with the back ones, recognizing only front and back vowels. As thus, the reader is at liberty to choose either account. 
As mentioned previously, the nucleus of the syllable may be either short (see Figure 1) or long ${ }^{4}$. Consider, for example, the following:

5) nū.pe.pa (newspaper): C(V:). CV. CV

6) pā.ma (palm tree): $\mathrm{C}(\mathrm{V}:) . \mathrm{CV}$

7) kī.wī (television): $\mathrm{C}(\mathrm{V}:) . \mathrm{CV}$

8) è.ko.na (corn): V: .CV.CV

According to Gussenhoven and Jacobs (2011: p. 46), a sequence of two vowels yield a (1) diphthong if the second vowel is higher than the first one or (2) a long vowel if the two sounds are identical. In both cases, monosyllabicity is still retained (Figure 3). All other sequences of vowels are divided over two syllables (Figure 4). Consider, for example, the following:

9) lai. ki (rice): (CVV). CV

10)ku. a. po (belt)

Unlike (7) where the sequence of vowels yields a diphthong, representation (8) does not do so because the second vowel is lower than the first one. This situation mandates that the sequence be broken up and the second vowel be carried over to the next syllable. The second syllable [a] conforms to the most unmarked form, while

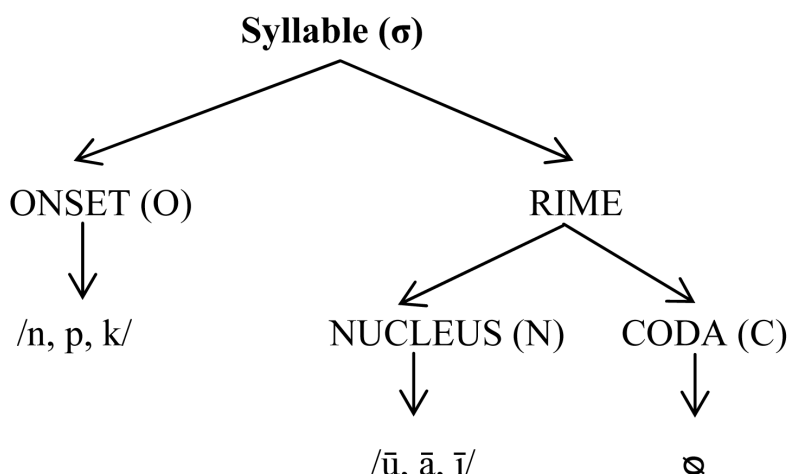

Figure 2. Universally unmarked syllable in Hawaiian (CV:).

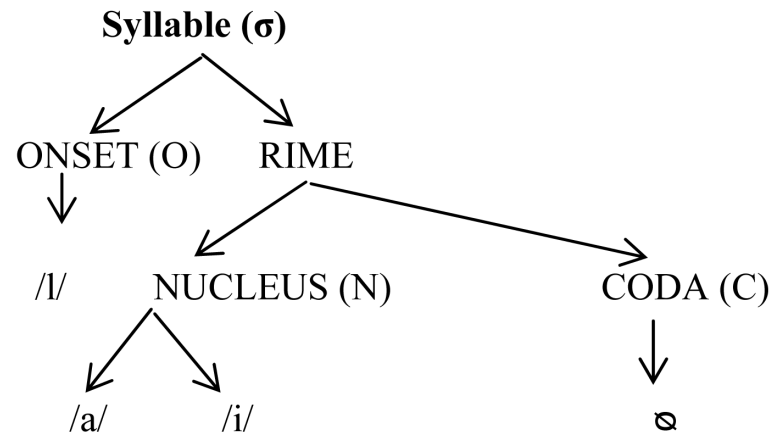

Figure 3. A monosyllabic representation of Hawaiian diphthong.

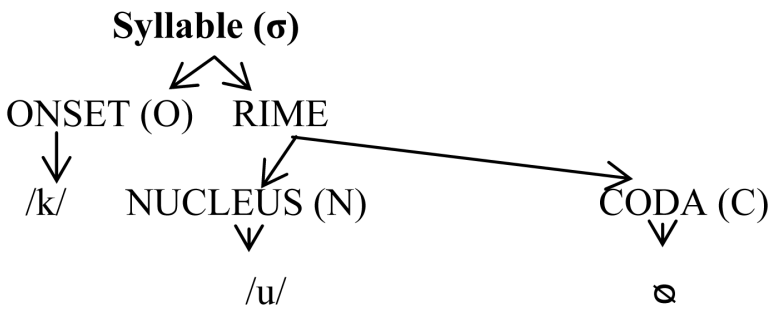

Figure 4. A sequence of two vowels divided over two syllables.

${ }^{4}$ Long vowels may be used as either [ū] or [u:] interchangeably in this paper. 
[ap] as opposed to [po] would yield a violation of no-coda constraint (*NO CODA). Further clarification will be furnished below.

Thus far, we have established that the syllable structure of Hawaiian can be described as a coda-less syllable of the following forms: (1) V or (2) CV. Alternatively, these two forms can be called free or open syllables. The opposite (closed or checked syllable) is prohibited in Hawaiian, e.g., VC, CVC, CVCC, etc.

\subsection{Light vs. Heavy Syllables}

The distinction between heavy and light syllables has been a subject of hot debate. Three models have been proposed: a) CV Theory (McCarthy, 1979; Clements \& Keyser, 1983), b) X Slot Model (Levin, 1985), and c) Moraic Theory (Hyman, 1985; Hayes, 1989). Due to the many problems associated with the first two models, they will not be addressed in this paper and will not be pursued any further. The Moraic Theory (henceforth MT) has been deemed a better alternative in accounting for the syllable weight. According to MT, a light syllable has one mora (monomoraic). As such, the following syllable structures are said to be light:

a) V (see example 1)

b) CV (see example 2)

Heavy syllables, on the other hand, have two or more morae (bimoraic or trimoraic) and can be found as follows:

c) CV: (see examples 5 through 7)

d) V: (see example 8)

e) CVV (see example 9)

f) VV (e.g., ai.la "oil")

Altogether, Hawaiian has six basic syllable structures summarized below (Figure 5).

\section{Loanwords in Rule-Based Phonology Revisited}

In rule-based phonology, rules are often postulated to account for the changes observed in loanwords. According to Silverman (1992) and Yip (1993), such posited rules are hard to swallow given they belong neither to the donor language nor to the recipient language. An example may be helpful to illustrate. Let us consider the following example adopted from Gussenhoven and Jacobs (2011: p. 47):

1) melekalikimaka "Merry Christmas"
(a) $\mathrm{M}$
e $\operatorname{rr}$ i
$\mathrm{k} r$
(b) $\begin{array}{llll}M & \varepsilon & \mathrm{I} & \mathrm{i}\end{array}$
(c) $\begin{array}{llll}\mid & M & V & \mid\end{array}$
k
$\begin{array}{lllll} & \mid & v & \mid \\ \text { (d) } & \mathrm{M} & \mathrm{e} & \mathrm{l} & \mathrm{e} \\ & \mid & \mathrm{V} & \mid \\ \text { (e) } \mathrm{M} & \text { e } & 1 & \underline{\mathbf{e}}\end{array}$

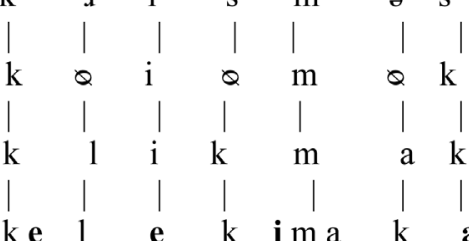
(English)
(Hawaiian)
(Phonemic Substitution)

Light Syllables

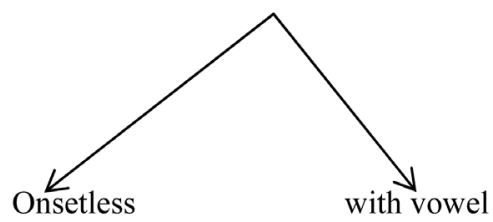

$\mathrm{V}$

[a.]

\section{Heavy Syllables}

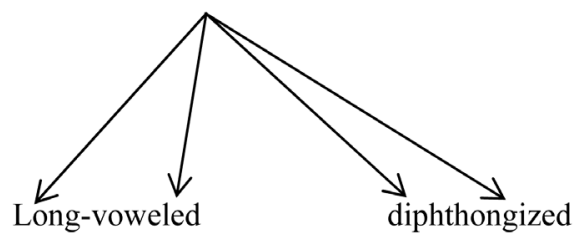

$\mathrm{V}: \quad \mathrm{CV}$ :

CVV VV

[ē.] [nū.]

[lai.]

[ai.]

* The dot [.] represents the syllable boundary. 
To account for the above-shown changes from a rule-based phonology perspective taking into account the syllable structure of Hawaiian (discussed below), the following rules are put forward:

\section{UR (Merry Christmas: English)}

$$
\begin{aligned}
& \text { Rule 1: Loss of Laxing } \\
& /- \text { ATR } / \rightarrow[+\mathrm{ATR}] \\
& / \varepsilon, \mathrm{I}, \mathrm{\partial} / \rightarrow[\mathrm{e}, \mathrm{i}, \mathrm{a}]
\end{aligned}
$$
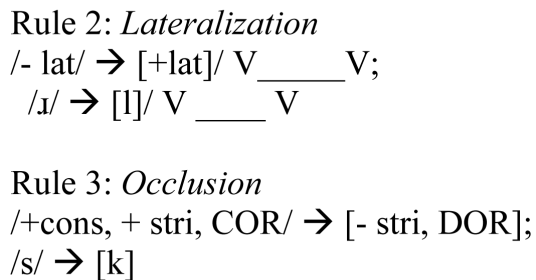

Rule 4: i-insertion

$$
\leftrightarrow \rightarrow \mathrm{V}_{\mathrm{i}} / \mathrm{V}_{\mathrm{i}} \mathrm{C} \_\{\mathrm{C}, \#\}
$$

\section{SR (me.leka.li.ki.ma.ka: Hawaiian)}

As can be seen, Rule 1 accounts for the English [-tense] vowels (i.e., [ع, I, ə]) changing into [+tense] vowel (i.e., [e, i, a]) in Hawaiian, respectively. Rule 2 accounts for the replacement [r] into [l] due being missing in Hawaiian. Rule 3 is responsible for changing English [s] into Hawaiian [k]. Finally, Rule 4 accounts for inserting [i] to declusterize (simplify or break up) between consonant clusters or [a] word-finally to preserve the syllable shape of Hawaiian, as we will see later in this paper.

At the level of detail we are considering here, we should mention that postulating rules is the one requirement of rule-based phonology. Nonetheless, this requirement of positing rules can be a tedious task and more importantly, fails to take into account that such posited rules are not necessarily applicable in either one of the two languages in contact. In other words, whereas Hawaiian lacks lax vowels, [r] and does not allow consonant clusters, the donor language (in our case English) allows lax vowels and permits consonant clusters with no need for the above-hypothesized rules. Simply put, these rules cannot be said to be universal. For this reason, we strongly believe that the need for a theoretical framework that has more explanatory power is urgent. We hope to show that the constraint-based approach (i.e., Optimality Theory) furnishes a relatively more adequate account of the phonology of loanwords, not only for Hawaiian but also cross linguistically.

\section{A Summary of Optimality Theory (OT)}

Optimality Theory (Prince \& Smolensky 1993, 1993a, 1993b; McCarthy \& Prince, 2004) states that Universal Grammar (UG) is best understood as a set of constraints, not rules. These constraints are universal, but individual languages rank them differently according to their degree of violation. The candidate that incurs the least number of violations (of highly ranked constraints) is said to be optimal. Alternatively, the candidate that incurs the most number of violations is ruled out. In a nutshell, Optimality Theory is about constraints and their violability. Figure 6 below shows the structure of OT.

\section{Data Collection \& Methodology}

Data necessary for this study consisted of some selected Hawaiian words adopted from Gussenhoven and Jacobs (2011: p. 51). These include the following:

$$
\text { hi (fire): } \quad \text { V. CV }
$$

Input $\longrightarrow$ GEN (Generator) $\Longrightarrow$ Candidate Set $\Longrightarrow$ EVAL (Evaluator) $\Longrightarrow$ Optimal Output

Figure 6. Structure of optimality theory. 


$\begin{array}{ll}\text { hi.pa (sheep): } & \text { CV.CV } \\ \text { ho.la (hour): } & \text { CV.CV } \\ \text { mahalo } & \text { CV.CV.CV } \\ \text { mahimahi } & \text { CV.CV.CV } \\ \text { ka.la (collar): } & \text { CV.CV } \\ \text { nū.pe.pa (newspaper): } & \text { C(V:). CV. CV } \\ \text { pā.ma (palm tree): } & \text { C(V:). CV } \\ \text { kī.wī (television): } & \text { C(V:). CV } \\ \text { è.ko.na (corn): } & \text { V:.CV.CV } \\ \text { lai. ki (rice): } & \text { (CVV). CV } \\ \text { ku. a. po (belt) } & \text { CV.V.CV } \\ \text { etc. } & \end{array}$

However, for our current analysis only two words will be used for demonstration purposes. These are as follows:

- English "ticket" is pronounced [kikiki]

- English "brush" is pronounced [palaki]

\section{Preliminary Remarks}

- Onset is optional, and if used no more than one consonant is allowed; so initial consonant clusters are prohibited;

- Nucleus is mandatory (either short or long);

- Codas (simple*C or complex*CC) are strictly prohibited.

In light of the above-mentioned observations, the following constraints can be formulated:

1) Markedness

- *CC: complex onset is prohibited

- *NO CODA: codas are prohibited.

2) Faithfulness (internal preservation)

- MAX-IO: no deletion of segments

$\checkmark$ MAX-V: no deletion of vowels

$\checkmark$ MAX-C: no deletion of consonants

- DEP-IO: no addition of segments

$\checkmark$ DEP-V: no addition of vowels

$\checkmark$ DEP-C: no addition of consonants

3) Possible phonological processes

- Epenthesis: vowel insertion (i.e., [i] or [a] $\left.{ }^{5}\right)$ to break up complex onsets ( $\left.{ }^{*} \mathrm{CC}\right)$ and preserve the unmarked form of the syllable structure $(\mathrm{C}) \mathrm{V}$

\section{Discussion and Analysis}

In this section, I will try to carefully examine the two Hawaiian words (i.e., kikiki and palaka) from an Optimality-Theoretic (OT) perspective, showing how the syllable structure of the borrowing language (BL: Hawaiian) will prevail over the syllable structure of the donor language (DL: English), given the set of constraints in effect in the borrowing language. Let us start by examining the first word.

\subsection{Discussion and Analysis: /kikik/ $\rightarrow$ [kikiki]}

The first word under investigation is the Hawaiian word kikiki / ki.ki.ki/, which is a loanword from English, i.e., ticket / tr.ktt. Given that Hawaiian lacks coronal obstruents (see Table 1), the newly formed representation is expected to be as follows:

\section{UR: / ticket/}

/t/> null (missing in borrowing language); replaced by closet corresponding segment /k/

\footnotetext{
${ }^{5}$ Strictly applicable to the two words investigated to this paper; other vowels can perhaps be epenthesized.
} 
$/ \mathrm{i} />[\mathrm{i}]$ (present in borrowing language)

$/ \mathrm{ck} />[\mathrm{k}]$ (present in borrowing language)

$/ \mathrm{i} />[\mathrm{i}]$ (present in borrowing language)

$/ \mathrm{t} />$ null (missing) but replaced by the closest corresponding segment $/ \mathrm{k} /$

\section{SR: [ ki.kik], [ ki.ki.k] or infinite (i.e., apple!)}

Needless to say, the above-rendered surface forms (SR) violate the syllable structure of Hawaiian (i.e., (C) V) in two aspects: (1) the first, namely ['ki.kik], contains a prohibited component; that is, a coda and (2) the second, namely ['ki.ki.k] lacks the mandatory nucleus. In OT terms, the first form violates a markedness constraint and the second violates that of faithfulness. Obviously, these constraints are in conflict. To solve this dilemma, constraints must be ranked to see which candidate form (i.e., optimal) will emerge victorious in this competition. Logically, a higher-ranked constraint (CON) will select a winning candidate (W), which in turn signals a fatal violation of the loser and a lower-ranked constraint will go with a losing candidate (L), which in turn signals the winning status of the winner. It follows that every constraint assessing $L$ must be dominated by some constrain assessing $\mathrm{W}$; for a winning candidate is preferred by a dominating constraint and a losing candidate is preferred by a less dominated constraint.

Prior to setting up the OT tableaux, it should be made clear that there is no limit (i.e., $\infty$ ) on the number of candidates GEN will generate. For our purposes however, we will limit ourselves to only two candidates-rendered above. Given this rather limited number of candidates, we deem it appropriate to consider all four constraints (CON) established above all at once. The comparative tableau, rather than the violation tableau, will guide us in determining the hierarchy of said constraints, i.e., setting up a ranking argument. Comparative Tableau 1 will do just that:

Comparative Tableau 1

\begin{tabular}{rcccc|}
\hline kikik $/[$ ki.ki.ki $]$ & ${ }^{*}$ NO CODA & DEP-IO & ${ }^{*}$ CC & MAX-IO \\
\hline ki.ki.ki $\sim$ Ki.kik & W & L & $e$ & $e$ \\
ki.ki.ki $\sim$ ki.ki & $e$ & L & $e$ & W
\end{tabular}

As seen, Comparative Tableau 1 sets up the ranking argument over a set of four constraints $\left(\Sigma\left\{C_{1}, C_{2}, C_{3}\right.\right.$, and $\left.\mathrm{C}_{4}\right\}$ ), which involves a comparison between the desired optimum (call it $\omega^{6}, q$ or whatever ${ }^{7}$ ) and the suboptimal competitor (call it $z, \mathrm{x}$ or whatever $^{8}$ ). Notice tableau lines are intentionally left dotted, as ranking has not been established yet. The constraint set $\Sigma\left\{\mathrm{C} 1, \mathrm{C}_{2} \cdots\right\}$ is divided into three disjointed subsets:

W: constraints that prefer $q$ to $z$; all $C \in \Sigma$ such that $q>z$

L: constraints that prefer $z$ to $q$; all $C \in \Sigma$ such that $z>q$

$e^{9}$ : constraints do equally well; all $C \in \Sigma$ such that $q \approx z$.

For a ranking argument to be set up efficiently and (most importantly) correctly, every L-assessing constraint must be preceded by at least one $\mathrm{W}$-assessing constraint. Put differently, every $\mathrm{C} \in L$ must be dominated by $D \in$ $W$. With this in mind (following the cogent logic of OT), one cannot help but notice that the above comparative tableau is wrongly formulated, that is, it contradicts the proposition just furnished, i.e., $\mathrm{D} \in W>\mathrm{C} \in L$. This is not to say that both rows are wrong. Rather it is only the second row vector that is false. The first row is correct and does pass the proposition because $\mathrm{C}_{2}$-assessing $\mathrm{L}$-comes after $\mathrm{C}_{1}$-assessing $\mathrm{W}$. To remedy the situation in an attempt to rectify our logic, one of two things can be done:

1) Looking for constraints that never prefer a suboptimal candidate (z) (constraints that prefer only a desired optimal candidate $(q)$ and/or prefer none $(e)$ ) and placing them at the top of the ranking;

2) Removing such top-ranked constraints from consideration along with the ranking argument.

Both options may be appealing, but one is more efficient (or desired) than the other-so to speak in OT terms. Starting with option two (rather than one), we will end up with the same problem, but only reduced in size. In

\footnotetext{
${ }^{6}$ Omega

${ }^{7}$ I will just go with $q$ thereafter.

${ }^{8}$ I will just go with $z$ thereafter.

${ }^{9}$ In the comparative tableau, $e$ will appear as either $e$ or blank.
} 
other words, removing top-ranked constraints (W-assessing constrains) will yield no argument to be made possible. In OT terms, the comparison is said to be inconsistent if its comparative tableau contains all rows that sum to $\mathrm{L}$ (i.e., $L$ summation). No comparison of this type will make $q$ optimal.

Comparative Tableau 2

\begin{tabular}{cc}
\hline kikik/ $\sim[$ ki.ki.ki] & DEP-IO \\
\hline ki.ki.ki $\sim$ Ki.kik & L \\
ki.ki.ki $\sim$ ki.ki & L \\
\hline
\end{tabular}

As seen in the Comparative Tableau 2, both rows contain L, which renders an inconsistent comparison. Therefore, neither a comparison nor a ranking can be spoken of in accordance with the premises of OT. Simply put, option two above is ruled out and will not be pursued any further for this word (i.e., kikiki) and the next one (i.e., palaki) accordingly.

Choosing option one (see above) over option two will yield a much more efficient comparison over the set of constraints as seen in Comparative Tableau 3 below.

Comparative Tableau 3

\begin{tabular}{cccc}
\hline$/$ kikik $\sim[$ ki.ki.ki $]$ & "NO CODA & MAX-IO & *CC \\
\hline ki.ki.ki $\sim$ Ki.kik & W & DEP-IO & L \\
ki.ki.ki $\sim$ ki.ki & & W & L \\
\hline
\end{tabular}

As obvious, MAX-IO (originally $\mathrm{C}_{4}$ ) was located and moved further to the left of the tableau and acquired a new ranking; that is, $\mathrm{C}_{2}$. Similarly, ${ }^{*} \mathrm{CC}$ (originally $\mathrm{C}_{3}$ ) kept its ranking status by virtue of place. Notice no ranking has been established for $\mathrm{C}_{1}$ through $\mathrm{C}_{3}$, hence the use of dotted lines. However, a solid line has been inserted between $C_{1}$ through $C_{3}$ and $C_{4}$ for we have established the relative ranking thus far. This can be represented in the following algorithmic formula:

$$
\Sigma_{1}\{\text { NO CODA, MAX-IO, *CC }\}>>\Sigma_{2}\{\text { DEP-IO }\}
$$

Of this, we know that if $\Sigma_{1}$ dominates $\Sigma_{2}$, then it follows that the content of $\Sigma_{1}$ also dominates the content of $\Sigma_{2}$. Put differently, $\mathrm{C}_{4}$ is dominated by $\mathrm{C}_{1}, \mathrm{C}_{2}$, and $\mathrm{C}_{3}$. Nonetheless, we still have not figured the ranking hierarchy inside $\Sigma_{1}$, i.e., we do not know what dominates what inside constrain set $\Sigma_{1}$.

To simplify the process of relative ranking of $\Sigma_{1}$ \{NO CODA, MAX-IO, $\left.{ }^{*} \mathrm{CC}\right\}$, we will exclude the constraint *CC as it does not assess a leftmost $\mathrm{W}$ and does not work in our analysis. Therefore, due to its inertness, *CC will be excluded (at least temporarily). Accordingly, we will be left with Comparative Tableau 4 below.

Comparative Tableau 4

\begin{tabular}{cccc}
\hline$/$ kikik/ $\sim[$ ki.ki.ki $]$ & *NO CODA & MAX-IO & DEP-IO \\
\hline ki.ki.ki $\sim$ Ki.kik & W & W & L \\
ki.ki.ki $\sim$ ki.ki & & W \\
\hline
\end{tabular}

Comparative Tableau 4 clearly shows that relative ranking has been established between C1 and C2 on the one hand and C3 on the other hand. That is, both C1 and C2 dominate C3. However, a dotted line still shows between markedness constraint *NO CODA and faithfulness constrain MAX-IO. Establishing the ranking order between these two constraints (at this stage) should be no hassle and is easily spotted. (*NO CODA) is never dominated in Hawaiian, which places it as the top of the ranking pyramid. It follows that MAX-IO must be dominated by *CC-a universally unmarked component of the Hawaiian syllable structure. Thus, the new constrain ranking is as follows (also see Comparative Tableau 5)

$$
\{* \text { NO CODA }>>\text { MAX-IO }>>\text { DEP-IO }\}
$$


Comparative Tableau 5

\begin{tabular}{cccc}
\hline$/$ kikik/ $\sim[$ ki.ki.ki $]$ & ${ }^{*}$ NO CODA & MAX-IO & DEP-IO \\
\hline ki.ki.ki $\sim$ Ki.kik & $\mathrm{W}$ & $e$ & $\mathrm{~L}$ \\
ki.ki.ki $\sim$ ki.ki & $e$ & $\mathrm{~W}$ & $\mathrm{~L}$ \\
\hline
\end{tabular}

If we were to add *CC (which we deemed appropriate to exclude temporarily), we would still be inclined to rank it above DEP-IO but lower than both *NO CODA and MAX-IO. Comparative Tableau 6 supports our ranking.

$$
\begin{gathered}
\text { If *NO CODA }>>\text { DEP-IO \& *CC }\}\left(\mathrm{C}_{1}>>\mathrm{C}_{4} \& \mathrm{C}_{3}\right) \& \\
\text { If MAX-IO }>>\text { DEP-IO }\left(\mathrm{C}_{2}>>\mathrm{C}_{4}\right) ; \\
\text { Then, } * \text { CC }<<* \text { NO CODA and MAX-IO }\left(\mathrm{C}_{1}>>\mathrm{C}_{3} \& \mathrm{C}_{2}\right)
\end{gathered}
$$

Comparative Tableau 6

\begin{tabular}{ccccc}
\hline kikik/ $\sim[$ ki.ki.ki] & ${ }^{*}$ NO CODA & MAX-IO & ${ }^{*}$ CC & DEP-IO \\
\hline ki.ki.ki $\sim$ Ki.kik & $W$ & $e$ & $e$ & $L$ \\
ki.ki.ki $\sim$ ki.ki & $E$ & $W$ & $e$ & $L$ \\
Ki.ki.ki. $\sim$ ki.kki & $W$ & $e$ & $W$ & $e$ \\
\hline
\end{tabular}

Thus, the new order must be as follows: $\{$ NO CODA $>>$ MAX-IO $>$ *CC $>>$ DEP-IO\}. With the above-established constraint ranking hierarchy, let us go ahead and set up the second type of tableaux; that is, a violation

\begin{tabular}{|c|c|c|c|c|}
\hline /kikik/ & ${ }^{*} \mathrm{NO}$ CODA & MAX-IO & ${ }^{*} \mathrm{CC}$ & DEP-IO \\
\hline 1. Kikk.i & ${ }^{*} !$ & * & & * \\
\hline 2. Ki.kik & $* !$ & & & \\
\hline 3. ki.ki & & ${ }^{*} !$ & & \\
\hline 4. Ki.kki & & & ${ }^{*} !$ & * \\
\hline 5. Ki.ki.ki & & & & * \\
\hline
\end{tabular}
tableau.

Violation Tableau 1

Violation Tableau 1 shows five possible candidates generated by GEN. Candidates (1) and (2) are ruled out for fatally violating *NO CODA (i.e., the first and the second syllable, respectively). Candidate (2) is also eliminated because it violates the MAX-IO constraint for not having a correspondent for the segment $[\mathrm{k}]$ in the output. Candidate (3) is also eliminated for violating the *CC (COMPLEX ONSET) constraint, explicitly, for having two consonants in the ONSET in the second syllable. Additionally, candidate (3) violates the low-ranked constraint of DEP-IO. Candidate (4) is optimal for incurring the least number of violations, i.e., the lowestranked constraint.

\subsection{Discussion and Analysis: /plak/ $\rightarrow$ [palaki]}

The second word studied in this paper is Hawaiian /palaki/, which is a loanword from English / 'brush/. Given that Hawaiian phonemic inventory is rather limited (i.e., m, n, p, k, h, ?, l, w) as previously established, the newly formed representation is expected to be as follows:

\section{UR: /brush/}

$\mathrm{B}>\mathrm{p}$ (missing in borrowing language); replaced by closet corresponding segment /p/

$\mathrm{r}>\mathrm{l}$ (missing in borrowing language); replaced by closet corresponding segment $/ \mathrm{l} /$

$\mathrm{u}>\mathrm{a} / \mathrm{plosive}$ plosive (present in borrowing language, but undergoes change) 
$\breve{s}>\mathrm{k}$ (missing in borrowing language); replaced by closest corresponding segment $/ \mathrm{k} /$

\section{SR: [’plak], [’pla.k], [pl.a.k], etc.}

Following the same hierarchy order established in 1 above, we will just use this second Hawaiian word /palaki/ to test the logical soundness of the established hierarchy. In other words, the goal in examining the second word will be solely to see whether or not this ranking is respected by all the data from the language itself. As such, explanations may be shorter as to eliminate redundancy and unneeded stuffing.

Comparative Tableau 7

\begin{tabular}{|c|c|c|c|c|}
\hline /plak/ [pa.la.ki] & ${ }^{*} \mathrm{NO}$ CODA & DEP-IO & ${ }^{*} \mathrm{CC}$ & MAX-IO \\
\hline pa.la.ki Pla & & $\mathrm{L}$ & $\mathrm{W}$ & \\
\hline pa.la.ki $\sim$ Pa.la & & $\mathrm{L}$ & & $\mathrm{W}$ \\
\hline pa.la.ki Plak & $\mathrm{W}$ & $\mathrm{L}$ & $\mathrm{W}$ & \\
\hline pa.la.ki Pa.lak & $\mathrm{W}$ & & & \\
\hline pa.la.ki Pla.ki & E & & $\mathrm{L}$ & \\
\hline
\end{tabular}

Comparative Tableau 7 sets up a ranking argument over a set of four unranked constraints. One cannot help but notice that rearrangement is required to rectify the logic and soundness of the argument. Doing so will give us Comparative Tableau 8.

Comparative Tableau 8

\begin{tabular}{|c|c|c|c|c|}
\hline /plak/ [pa.la.ki] & "NO CODA & MAX-IO & DEP-IO & ${ }^{*} \mathrm{CC}$ \\
\hline pa.la.ki Pla & & & $\mathrm{L}$ & W \\
\hline pa.la.ki Pa.la & & W & $\mathrm{L}$ & \\
\hline pa.la.ki Plak & $\mathrm{W}$ & & $\mathrm{L}$ & W \\
\hline pa.la.ki Pa.lak & $\mathrm{W}$ & & & \\
\hline pa.la.ki Pla.ki & $\mathrm{W}$ & & & $\mathrm{L}$ \\
\hline
\end{tabular}

As can be seen from the above Tableau, a new hierarchy is in order as follows:

$$
\Sigma_{1}\{\text { NO CODA, MAX-IO, DEP-IO }\}>>\Sigma_{2}\left\{{ }^{*} \mathrm{CC}\right\}
$$

The newly proposed hierarchy of ranking still presents a flaw that we believe can be easily rectified through rearranging the constraints as follows:

$$
\Sigma_{1}\{\mathrm{NO} \text { CODA }>>\text { MAX-IO }\}>\Sigma_{2}\{\text { DEP-IO, *CC }\}
$$

\begin{tabular}{|c|c|c|c|c|}
\hline /plak/ [pa.la.ki] & ${ }^{*} \mathrm{NO}$ CODA & MAX-IO & DEP-IO & ${ }^{*} \mathrm{CC}$ \\
\hline pa.la.ki Pla & & & $\mathrm{L}$ & $\mathrm{W}$ \\
\hline pa.la.ki Pa.la & & W & $\mathrm{L}$ & \\
\hline pa.la.ki Plak & W & & $\mathrm{L}$ & W \\
\hline pa.la.ki Pa.lak & W & & & \\
\hline pa.la.ki Pla.ki & $\mathrm{W}$ & & & $\mathrm{L}$ \\
\hline
\end{tabular}

Comparative Tableau 9

Tableau 9 above places both $\Sigma_{1}$ \{NO CODA and MAX-IO $\}$ higher than $\Sigma_{2}$ \{DEP-IO and $\left.{ }^{*} \mathrm{CC}\right\}$. Given that every L-assessing constraint must be preceded by a $\mathrm{W}$-assessing constraint, a new ranking is in order. This can be seen in Comparative Tableau 10 below. 
Comparative Tableau 10

\begin{tabular}{|c|c|c|c|c|}
\hline /plak/ [pa.la.ki] & ${ }^{*} \mathrm{NO}$ CODA & MAX-IO & ${ }^{*} \mathrm{CC}$ & DEP-IO \\
\hline pa.la.ki Pla & & & W & $\mathrm{L}$ \\
\hline pa.la.ki Pa.la & & W & & $\mathrm{L}$ \\
\hline pa.la.ki Plak & $\mathrm{W}$ & & $\mathrm{W}$ & $\mathrm{L}$ \\
\hline pa.la.ki Pa.lak & $\mathrm{W}$ & & & \\
\hline pa.la.ki Pla.ki & $\mathrm{W}$ & & $\mathrm{L}$ & \\
\hline
\end{tabular}

Comparative Tableau 10 above accounts for all possible candidates and further confirms the previously established hierarchy ranking as follows:

$$
\Sigma\{\text { NO CODA }>>\text { MAX-IO }>>* \text { CC }>>\text { DEP-IO }\}
$$

Obviously, the established ranking used in examining the first word proves itself to be logically free of flaws and inconsistencies; it furnished confirmatory evidence of the soundness of the ranking hierarchy previously established and adopted thereafter. With this in mind, we move on to construct the second type of tableaux; that is, a violation tableau.

Violation Tableau 2

\begin{tabular}{|c|c|c|c|c|}
\hline /plak/ [pa.la.ki] & ${ }^{*} \mathrm{NO}$ CODA & MAX-IO & ${ }^{*} \mathrm{CC}$ & DEP-IO \\
\hline 1. [Pla] & & ${ }^{*} !$ & * & \\
\hline 2. [Pa.la] & & ${ }^{*} !$ & & * \\
\hline 3. [Plak] & ${ }^{*} !$ & & $*$ & \\
\hline 4. [Pa.lak] & ${ }^{*} !$ & & & * \\
\hline 5. [Pla.ki] & & & * & * \\
\hline 6. [Pa.la.ki] & & & & * \\
\hline
\end{tabular}

Violation Tableau 2 above presents six candidate forms compared over four constraints. Candidate (1) is ruled out for fatally violating MAX-IO along with violating a lower-ranked constrained, namely, *CC. Candidate (2) is also eliminated from the competition for also fatally violating MAX-IO along with inserting a segment (i.e., [a]) in the output that is not present in the input. Both Candidates (3) and (4) are also ruled for violating the highly ranked constraint *NO CODA, specifically, embracing a coda in the first syllable and second syllables of (3) and (4), respectively. Candidate (5) incurs two lower-ranked violations, namely, *CC and DEP-IO. Candidate (6) has emerged victorious for incurring the least number and most importantly least serious of all violations, i.e., DEP-IO.

\section{Conclusion}

This paper has sought to provide an Optimality-Theoretic (OT) account of two Hawaiian words borrowed from English. The OT framework is adopted to provide a complete analysis of the syllable structure of these two loanwords in Hawaiian. Several constraints were hypothesized to account for what is permitted and what is prohibited in the syllable shape of Hawaiian loanwords. In addition, the logic of Optimality Theory was briefly described, introducing both types of tableaux used in OT analyses. This study is significant as no other studies have tackled the subject of loanwords, particularly, English loanwords in the Hawaiian language from an OT perspective. Nevertheless, the study may be limited as it examines only two English loanwords in Hawaiian. Future studies are highly recommended as to test our suggested ranking argument against further data from Hawaiian.

\section{References}

Clements, G. N., \& Keyser, S. J. (1983). CV Phonology: A Generative Theory of the Syllable. Cambridge, MA: MIT Press. http://dx.doi.org/10.1017/CBO9780511611834 
Gumperz, J. (1982). Discourse Strategies. Cambridge: Cambridge University Press.

Gussenhoven, C., \& Jacobs, H. (2011). Understanding Phonology: Understanding Language (3rd ed.). London: Hodder Education.

Hayes, B. (1989). Compensatory Lengthening in Moraic Phonology. Linguistic Inquiry, 20, 253-306.

Hyman, L. (1985). A Theory of Phonological Weight. Dordrecht: Foris Publications.

Jones, Ō. P. (n.d.). Loanwords in Hawaiian. University of Oxford. http://www.ling-phil.ox.ac.uk/pj_pubs

Kaiao, M. (2003). Modern Hawaiian Vocabulary. Honolulu, HI: University of Hawaii Press.

Levin, J. (1985). A Metrical Theory of Syllabicity. Ph.D. Dissertation, Cambridge, MA: MIT.

Maddieson, I. (2011). Consonant Inventories. In M. S. Dryer, \& M. Haspelmath (Eds.), The World Atlas of Language Structures Online. Munich: Max Planck Digital Library.

McCarthy, J. (1979). Formal Problems in Semitic Phonology and Morphology. Unpublished Ph.D. Dissertation, Cambridge, MA: MIT.

McCarthy, J., \& Prince, A. (1993a). Prosodic Morphology I: Constraint Interaction and Satisfaction. Amherst, MA: University of Massachusetts and New Brunswick, NJ: Rutgers University.

McCarthy, J., \& Prince, A. (1993b). Generalized Alignment. Amherst, MA: University of Massachusetts. http://scholarworks.umass.edu/linguist_faculty_pubs/12/

Prince, A., \& Smolensky, P. (2004).Optimality Theory: Constraint Interaction in Generative Grammar. Malden, MA: Blackwell. http://dx.doi.org/10.1002/9780470759400

Prince, A., \& Smolensky, P. (1993). Optimality Theory: Constraint Interaction in Generative Grammar (Technical Report no. RuCCS-TR-2). New Brunswick, NJ: Rutgers University Center for Cognitive Science.

Elbert, S., \& Pukui, M. (1979). Hawaiian Grammar. Honolulu, HI: University Press of Hawaii.

Reinecke, J. (1969). Language and Dialect in Hawaii: A Sociolinguistic History to 1935. Honolulu, HI: University of Hawai'i Press.

Silverman, D (1992). Multiple Scansions in Loanword Phonology: Evidence from Cantonese. Phonology, 9, $289-328$. http://dx.doi.org/10.1017/S0952675700001627

US Census Bureau (2009). Language Use in the United States. US Census Bureau. http://www.census.gov/hhes/socdemo/language/

Yip, M. (1993). Cantonese Loanword Phonology and Optimality Theory. Journal of East Asian Linguistics, 2, 261-291. http://dx.doi.org/10.1007/BF01739135

\section{Submit or recommend next manuscript to SCIRP and we will provide best service for you:}

Accepting pre-submission inquiries through Email, Facebook, Linkedin, Twitter, etc A wide selection of journals (inclusive of 9 subjects, more than 200 journals)

Providing a 24-hour high-quality service User-friendly online submission system

Fair and swift peer-review system

Efficient typesetting and proofreading procedure

Display of the result of downloads and visits, as well as the number of cited articles

Maximum dissemination of your research work

Submit your manuscript at: http://papersubmission.scirp.org/ 